\title{
Momordica charantia, a Nutraceutical Approach for Inflammatory Related Diseases
}

\author{
Massimo Bortolotti ${ }^{1}$, Daniele Mercatelli ${ }^{1,2}$ and Letizia Polito ${ }^{1 *}$ \\ 1 Department of Experimental, Diagnostic and Specialty Medicine-DIMES, Alma Mater Studiorum, University of Bologna, \\ Bologna, Italy, ${ }^{2}$ Department of Pharmacy and Biotechnology, Alma Mater Studiorum, University of Bologna, Bologna, Italy
}

\section{OPEN ACCESS}

Edited by:

Ilaria Peluso,

Council for Agricultural

and Economics Research, Italy

Reviewed by:

Mohammed Rahmatullah, University of Development Alternative,

Bangladesh

Elena Azzini,

The Council for Agricultural Research and Economics, Italy Jimmy Thomas Efird,

University of Newcastle, Australia

${ }^{*}$ Correspondence: Letizia Polito

letizia.polito@unibo.it

Specialty section: This article was submitted to Inflammation Pharmacology,

a section of the journal

Frontiers in Pharmacology

Received: 29 January 2019

Accepted: 17 April 2019

Published: 08 May 2019

Citation:

Bortolotti M, Mercatelli D and Polito L (2019) Momordica charantia, a Nutraceutical Approach

for Inflammatory Related Diseases.

Front. Pharmacol. 10:486.

doi: 10.3389/fphar.2019.00486
Momordica charantia, commonly called bitter melon, is a plant belonging to Cucurbitaceae family known for centuries for its pharmacological activities, and nutritional properties. Due to the presence of many bioactive compounds, some of which possess potent biological actions, this plant is used in folk medicine all over the world for the treatment of different pathologies, mainly diabetes, but also cancer, and other inflammation-associated diseases. It is widely demonstrated that $M$. charantia extracts contribute in lowering glycaemia in patients affected by type 2 diabetes. However, the majority of existing studies on $M$. charantia bioactive compounds were performed only on cell lines and in animal models. Therefore, because the real impact of bitter melon on human health has not been thoroughly demonstrated, systematic clinical studies are needed to establish its efficacy and safety in patients. Besides, both in vitro and in vivo studies have demonstrated that bitter melon may also elicit toxic or adverse effects under different conditions. The aim of this review is to provide an overview of anti-inflammatory and anti-neoplastic properties of bitter melon, discussing its pharmacological activity as well as the potential adverse effects. Even if a lot of literature is available about bitter melon as antidiabetic drug, few papers discuss the anti-inflammatory and anti-cancer properties of this plant.

\section{Keywords: Momordica charantia, bitter melon, bitter gourd, natural products, nutraceuticals, anti-inflammatory} agents, anti-cancer agents

\section{TRADITIONAL USES OF Momordica charantia}

Momordica charantia L. (MC), also known as bitter melon or bitter gourd, belongs to Cucurbitaceae family and grows in tropical and sub-tropical regions. The fruits and leaves of Momordica species are rich in phytochemicals and may have many health-promoting effects by offering nutritional and nutraceutical components. The plant has been known for ages and it has been used in many traditional and folk medicines (Polito et al., 2016a) for a wide range of medical applications, including the treatment of T2DM, hypertension, obesity, cancer, bacterial and viral infections, and even AIDS (Grover and Yadav, 2004). In Ayurveda medicine, bitter melon, known as karela,

Abbreviations: ERK, extracellular signal-regulated kinases; IL, interleukin; IT, immunotoxin; JNK, c-Jun N-terminal kinases; LPS, lipopolysaccharide; MAP30, Momordica anti-viral protein of $30 \mathrm{kDa}$; MAPKs, mitogen-activated protein kinases; MC, Momordica charantia; NF-אB, nuclear factor kappa-light-chain-enhancer of activated B cells; NO, nitric oxide; RIP, ribosome-inactivating-protein; T2DM, type 2 diabetes mellitus; TNF- $\alpha$, tumor necrosis factor-alpha. 
has been used for thousands of years. Its pharmacological properties are attributed to each part of the plant, i.e., seeds, roots, leaves, and particularly the unripe fruits (Scartezzini and Speroni, 2000). The juice found application for the treatment of many disorders: for example, it is used for joint pain relief and against chronic fever, in cases of jaundice and illnesses of the liver or the digestive system because of its diuretic, laxative and anti-helminthic actions. It is applied locally in case of chronic skin diseases and to treat burns, boils, and rashes. The use of the whole plant as food is recommended for the treatment of T2DM (Scartezzini and Speroni, 2000). In Turkish folk medicine the oil obtained from the ripe fruits of bitter melon, macerated in olive oil warmed by the sun, was combined with honey, and used for the prevention and healing of gastric ulcers (Gürdal and Kültür, 2013). In African folk medicine bitter melon is mainly used for worm infections, inflammation (fruits, seeds, and leaf juice), fever, menorrhea (leaves), syphilis, rheumatism, and skin diseases (roots). Leaf decoction is used in T2DM patients; fruits and leaves are used for the treatment of jaundice and other liver diseases and to cure ulcers and burns. Moreover, Momordica preparations are given for the treatment of gonorrhea, measles, chicken pox, scabies and malaria. In the Caribbean area, it is administered as a leaf decoction or fruit juice for the treatment of diabetes. The leaf decoction is also used for the treatment of high blood pressure, womb infections, malaria, dysentery, and worm infections. Leaf baths are used for rheumatism therapy (Polito et al., 2016a).

\section{CHEMICAL CONSTITUENTS AND NUTRITIONAL VALUE OF Momordica charantia}

The major chemical constituents of MC are classified as: (i) heteropolysaccharides, mainly composed of galactose, glucose, arabinose, rhamnose, and mannose; (ii) proteins and peptides, such as momordins, momorcharins, MAP30 and MC lectin, belonging to the ribosome-inactivating proteins family (RIPs) (Schrot et al., 2015); (iii) terpenoids and saponins, such as cucurbitanes and cucurbitacines; (iv) flavonoids and phenolic compounds; (v) other compounds such as essential oils, fatty acids, amino acids, and sterols (Dandawate et al., 2016). Chemical structures of the main bioactive MC constituents are reported in Supplementary Figure S1.

Nutritional analysis demonstrated that this plant possesses the highest nutritive value among cucurbits, being a good source of carbohydrates, proteins, fibers, vitamins, and minerals. Fruits are composed by $93.2 \%$ of water, while protein and lipids account for 18.02 and $0.76 \%$ of its dried weight, respectively (Saad et al., 2017). Green fruits contain vitamin C, A and $\mathrm{P}$, thiamine, riboflavin, niacin, and minerals (Gupta et al., 2011). In addition, MC seeds can represent a good source of lipids, such as polyunsaturated fatty acids (nearly $45 \%$ of the weight) and they are among the few foods containing conjugated linolenic acid, being 63-68\% as eleostearic acid (Yoshime et al., 2016). The essential oil, obtained from drought seeds, contains sesquiterpenes, phenylpropanoids and monoterpenes. Other bioactive compounds, such as tocopherols and polyphenols have been reported in MC seed oil (Nyam et al., 2013). The pericarp, the aril, the stem and the leaves of the plant are also a good source of phenolic compounds, which can be useful to protect from oxidative damage by acting directly on reactive oxygen species and to induce endogenous defense systems (Yoshime et al., 2016).

Several glycosides isolated from MC fruit and stem have been grouped as cucurbitane-type triterpenoids, being cucurbitacins the main ones. They exhibit a broad range of biological activities, mainly anti-inflammatory and anti-diabetic (Rios et al., 2005).

\section{ANTI-INFLAMMATORY AND ANTI-OXIDANT ACTIVITY OF Momordica charantia}

Lifestyle and dietary habits contribute to a chronic state of lowgrade inflammation, which can alter immune status and gut microbiota. Various dietary components have the potential to modulate predisposition to chronic inflammatory conditions and can be helpful in their therapy. Nevertheless, the relationship among most of these dietary components and their antiinflammatory mechanisms is unclear (Minihane et al., 2015).

Momordica charantia dietary supplementation has been widely studied to treat several diseases, like T2DM, dyslipidemia, obesity and cancer, thus showing that MC extracts possess hypoglycemic and lipid-lowering properties, even if clinical trials conducted so far gave inconclusive results (Alam et al., 2015). In diabetic patients, the chronic systemic inflammation contributes to increase blood glucose concentration and represents a risk factor in developing cardiovascular diseases and obesity. Chronic inflammation is involved in the pathogenesis of different diseases: a clear association has been established for neurodegenerative diseases, obesity, metabolic syndrome, cardiovascular disease, T2DM, and cancer (Minihane et al., 2015). Several evidences indicate that oxidative stress plays a role in chronic inflammatory diseases. Thus, oxidative stress and inflammation are closely related pathophysiological processes that can activate each other (Biswas, 2016). MC beneficial properties seem dependent on its anti-inflammatory and anti-oxidant activities (Chao et al., 2014; Dandawate et al., 2016). Various MC extracts were found to regulate inflammation mainly through $\mathrm{NF}-\kappa \mathrm{B}$ signaling pathway inhibition: in RAW 264.7 cells, bitter melon reduced TNF- $\alpha$ production, induced by LPS, decreasing the expression of LPSinduced inflammatory genes, including those for IL- $1 \alpha$, IL-1 $\beta$, and TNF- $\alpha$. The MC extracts also reduced NF- $\kappa$ B DNA binding activity and phosphorylation of p38, JNKs, ERKs as well as MAPKs (Kobori et al., 2008a). Moreover, MC showed reduction of LPS-induced NO and prostaglandin E2 production together with a reduction of inducible NO synthase and IL-1 $\beta$ expression (Lii et al., 2009). In the same cell model, a dose-dependent inhibition of NO production for MC extract was demonstrated (Svobodova et al., 2017); but it was also reported that MC extracts reduced expression levels of inducible NO synthase and cyclooxygenase-2, suppressing NF- $\mathrm{B}$, and activator protein-1 (AP-1) activity via downregulation of ERKs and Akt (Hsu et al., 


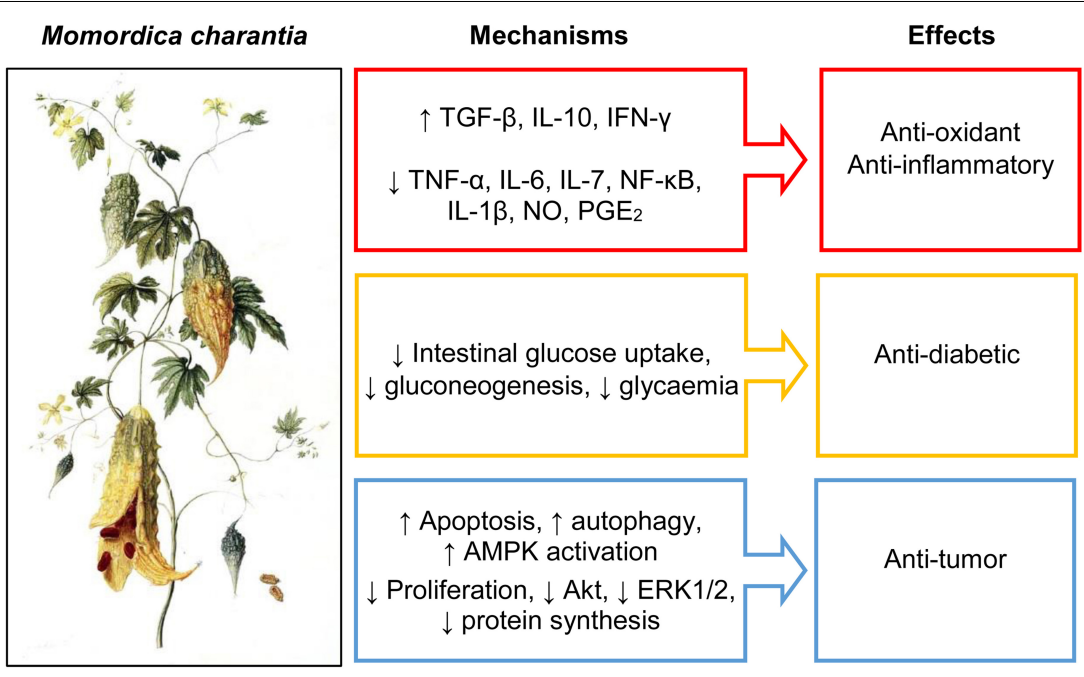

FIGURE 1 | Main mechanisms of Momordica charantia pharmacological effects.

2013; Yang et al., 2018). The effects of a triterpene purified from bitter melon was investigated against TNF- $\alpha$-induced inflammation via AMP-activated protein kinase in FL83B cells. This compound suppressed the TNF- $\alpha$-induced expression of inflammatory markers, including inducible NO synthase, p65 subunit of NF- $\kappa B$, TNF- $\alpha$, and IL-1 $\beta$ (Cheng et al., 2012). In C57BL/6 mice fed with high-fat diet supplemented with MC, a decrease in serum C reactive protein and IL- 6 concentrations together with a loss of hyperglycemia and hyperlipidemia was reported (Xu et al., 2014). The MC-containing diet also normalized serum levels of the cytokines suggesting its role in reducing inflammation, obesity and insulin resistance in obese mice (Bao et al., 2013). Dietary supplementation with MC powder in high-fat diet obese mice was showed to lower systemic inflammation by reducing TNF- $\alpha$ and IL- 6 serum levels and to remodel key functions of colon by altering transcriptomic profile and affecting the expression of genes involved in the regulation of inflammation (Bai et al., 2016, 2018). Recently, it was reported that MC extracts reduced intercellular adhesion molecule-1 expression and upregulated mir-221/-222 in TNF$\alpha$ treated lung tissues in mice, also decreasing PI3K/Akt/NF$\kappa \mathrm{B} / \mathrm{I} \kappa \mathrm{B}$. MC extracts were given before TNF- $\alpha$, suggesting that bitter melon supplementation may be useful as a chemopreventive agent in individuals at risk for inflammatory-related diseases (Sung et al., 2018). Therefore, MC exerts its antiinflammatory effects by acting on several important signaling pathways involved in inflammation.

The potential anti-oxidant activity of MC extracts has been evaluated in several in vitro studies. Pretreatment of neuroblastoma cells with MC extracts was found to attenuate cytotoxic oxidative stress induced by $\mathrm{H}_{2} \mathrm{O}_{2}$ by increasing intracellular scavenger activity and reducing $\mathrm{H}_{2} \mathrm{O}_{2}$ induced activation of the JNKs, p38, and ERK1/2 MAPK signaling pathways (Kim et al., 2018). MC fruit extract significantly reduced neuro-inflammation, ameliorating the consequent neurodegenerative diseases (Nerurkar et al., 2011).
Xanthine oxidase is a key enzyme for the induction of hyperuricemia and gout and it is involved in many inflammation related diseases, such as metabolic syndrome, and in augmented cancer risk (Battelli et al., 2016, 2018). Cucurbitane-type triterpene glycosides isolated from MC stems and fruits significantly inhibit xanthine oxidase activity (Lin et al., 2012). Triterpenoids isolated from MC stems have also shown scavenging activities and inhibitory effect on xanthine oxidase activity (Liu et al., 2010). Anti-oxidant compounds in bitter gourd pulp and seed powders showed potential natural anti-oxidant activity to inhibit the lipid peroxidation (Padmashree et al., 2010). Moreover, MC was evaluated for its anti-oxidant activity in vitro showing an amelioration of oxidative damage induced by peroxynitrite (Kim et al., 2013). It has been demonstrated that, after blanching, bitter gourd considerably decreases its phenolic content and anti-oxidant activity (Myojin et al., 2008). Therefore, the MC anti-oxidant activity seems dependent both from direct radical scavenge of MC components and from their effect on oxidant enzymes.

Bitter melon extracts were also found to alleviate bacterialinduced inflammation. For example, MC extracts reduced Propionibacterium acnes-induced skin inflammation in mice and suppressed the cytokine and matrix metalloproteinase-9 levels in Propionibacterium acnes-induced inflammation of THP- 1 cells. This activity was attributed to the anti-inflammatory effects of phenolic compounds present in the extract (Huang et al., 2015). Cucurbitane triterpenods isolated from MC leaves strongly suppressed Porphyromonas gingivalis-induced IL-8, IL-6, and IL-1 $\beta$ levels (Tsai et al., 2016).

The anti-inflammatory activity of MC supplementation has been also demonstrated in patients with primary knee osteoarthritis, in a single-blinded, randomized trial. Thirty-eight patients were daily treated for 3 months with commercially available MC supplementation. After 3 months, there were significant improvements in knee osteoarthritis and reduction in analgesic score; also, body weight, body mass index, and fasting 
TABLE 1 | Main anti-oxidant and anti-inflammatory studies carried out in vitro and in vivo with MC components.

\begin{tabular}{|c|c|c|c|c|}
\hline $\begin{array}{l}\text { Pathological } \\
\text { process }\end{array}$ & Compound(s) & In vitro & Animals & References \\
\hline Inflammation & MC extract & & Mice & Deng et al., 2019 \\
\hline Oxidative stress & MC ethanol extract & SK-N-MC cells & & Kim et al., 2018 \\
\hline Oxidative stress & MC leaf ethanol extract & & Obese mice & He et al., 2018 \\
\hline Inflammation & MC extracts & & ApoE KO C57BL/6 mice & Zeng et al., 2018 \\
\hline Inflammation & MC powder & & $\begin{array}{l}\text { Obese Sprague-Dawley } \\
\text { rats }\end{array}$ & Bai et al., 2016, 2018 \\
\hline Inflammation & MC fruit extracts & A549 cells & C57BL/6 mice & Sung et al., 2018 \\
\hline $\begin{array}{l}\text { Oxidative } \\
\text { stress/inflammation }\end{array}$ & Bioactive peptide BG-4 & THP-1 cells & & Jones et al., 2018 \\
\hline $\begin{array}{l}\text { Oxidative } \\
\text { stress/inflammation }\end{array}$ & MC methanol extract & RAW264.7 cells & & $\begin{array}{l}\text { Lii et al., 2009; Yang et al., } \\
2018\end{array}$ \\
\hline $\begin{array}{l}\text { Oxidative } \\
\text { stress/inflammation }\end{array}$ & MC polysaccharides & $\begin{array}{l}\text { Oxidative stress cell free assays } \\
\text { Primary neuronal cells }\end{array}$ & $\begin{array}{l}\text { Gastritis/myocardial } \\
\text { infarction/ischemia- } \\
\text { reperfusion/rat } \\
\text { models }\end{array}$ & $\begin{array}{l}\text { Gong et al., 2015; Tan and } \\
\text { Gan, 2016; Raish, 2017; Raish } \\
\text { et al., } 2018\end{array}$ \\
\hline Inflammation & MC fruit juice & T-cells & Diabetic Wistar rats & Fachinan et al., 2017a,b \\
\hline $\begin{array}{l}\text { Oxidative } \\
\text { stress/inflammation }\end{array}$ & MC extract & & Holstein-Friesian cows & Emre et al., 2017 \\
\hline Oxidative stress & MC anthocyanins & Oxidative stress cell free assays & & Güdr, 2016 \\
\hline Oxidative stress & MC extract & Oxidative stress cell free assays & & $\begin{array}{l}\text { Padmashree et al., 2010; } \\
\text { Ghous et al., 2015; Aljohi et al., } \\
2016\end{array}$ \\
\hline Oxidative stress & $\begin{array}{l}\text { MC metanolic, ethanolic and } \\
\text { butanolic extracts }\end{array}$ & Oxidative stress cell free assays & & Yadav et al., 2016 \\
\hline Inflammation & MC leaf extract & $\begin{array}{l}\text { Porphyromonas gingivalis-induced } \\
\text { THP-1 stimulation }\end{array}$ & $\begin{array}{l}\text { Mice skin inflammation } \\
\text { model }\end{array}$ & $\begin{array}{l}\text { Huang et al., 2015; Tsai et al., } \\
2016\end{array}$ \\
\hline Inflammation & MC fruit and seeds extract & & BALB/c mice with sepsis & $\begin{array}{l}\text { Chao et al., 2014; Ciou et al., } \\
2014\end{array}$ \\
\hline Inflammation & MC fruit ethyl acetate extract & RAW 264.7 cells & & Hsu et al., 2013 \\
\hline Inflammation & MC fruits & & Obese C57BL/6 mice & Bao et al., 2013 \\
\hline Inflammation & Cucurbitane-type triterpene & RAW 264.7 cells; FL83B cells & & $\begin{array}{l}\text { Cheng et al., 2012; Liaw et al., } \\
2015\end{array}$ \\
\hline $\begin{array}{l}\text { Oxidative } \\
\text { stress/inflammation }\end{array}$ & MC aqueous extracts & & Obese mice; Diabetic rats & $\begin{array}{l}\text { Tripathi and Chandra, 2010; Xu } \\
\text { et al., } 2014\end{array}$ \\
\hline Inflammation & Butanol extract & RAW 264.7 cells & & Kobori et al., $2008 \mathrm{a}$ \\
\hline
\end{tabular}

blood glucose were significantly reduced. In this study, it was demonstrated that $\mathrm{MC}$ can represent an alternative to reducing pain and improving symptoms among patients while reducing the need for analgesic drug consumption (Soo May et al., 2018).

The main mechanisms of MC anti-inflammation and antioxidant actions are summarized in Figure 1. In Table 1 we summarized some of the main in vitro and in vivo studies conducted so far to investigate MC anti-inflammation and antioxidant actions.

\section{ANTI-CANCER ACTIVITY OF Momordica charantia}

Accumulating evidence shows that chronic inflammation can promote tumor initiation and malignant progression of many cancers. Two pathways linking inflammation and cancer are generally identified: (i) tumor-extrinsic inflammation, which is caused by many factors, including bacterial and viral infections, lifestyle and exposure to environmental pollutant, and it is mediated by innate immunity cells; (ii) tumor-intrinsic inflammation, which is due to neoplastic mutations leading to the production of inflammatory mediators and the recruitment of immunity cells in the tumor microenvironment, contributing in an inflammatory milieu promoting several steps of cancer progression. These two pathways share common features, such as the production of primary inflammatory cytokines like IL-1, IL6 , and TNF- $\alpha$ and the activation of known transcription factors involved in the regulation of inflammatory response, such as NF$\kappa \mathrm{B}$ and STAT3 (Marelli et al., 2017). Considering the importance of inflammatory changes in different cancer types, preventing or reversing inflammation has become an important approach to control neoplasia progression.

In Table 2 we summarized some of the main in vitro and in vivo studies conducted so far to investigate MC anticancer activity.

Several phytochemicals, including MC extracts, are described to possess promising potentials as adjuvants in conventional 
TABLE 2 | Main anti-tumoral studies carried out in vitro and in vivo with MC components.

\begin{tabular}{|c|c|c|c|c|}
\hline Tumor & Compound(s) & Cells & Animals & References \\
\hline \multirow[t]{7}{*}{ Breast } & Cucurbitane-type triterpene & MCF-7, MDA-MB-231 & & Weng et al., 2013 \\
\hline & RNase MC2 & MCF-7 & & Fang et al., 2012a \\
\hline & MC extract & MCF-7, MDA-MB-231 & & Ray et al., 2010 \\
\hline & Eleostearic acid & MDA-ER $\alpha 7$ & & Grossmann et al., 2009 \\
\hline & Water MC extract & & SHN mice & Nagasawa et al., 2002 \\
\hline & MAP30 & MDA-MB-231 & SCID mice & Lee-Huang et al., 2000 \\
\hline & $\alpha$-momorcharin & MCF-7, MDA-MB-231, MDAMB-453 & Balb/C mice & Cao et al., 2015 \\
\hline \multirow[t]{7}{*}{ Colon } & Methanol MC extract & HT-29, SW480, HFF & & Kwatra et al., 2013 \\
\hline & Methanol MC extract & Hone-1, AGS, HCT-116, CL1-0 & & Li et al., 2012a \\
\hline & Acid and alkali MC extracts & SGC-7901 & & Li et al., 2012b \\
\hline & MAP30 & LoVo & & Fan et al., 2008 \\
\hline & MC fatty acids & Caco-2 & & Yasui et al., 2005 \\
\hline & MC extract & & Swiss mice & Deep et al., 2004 \\
\hline & MC extract & & F344 rats & Kohno et al., 2004 \\
\hline \multirow[t]{4}{*}{ Liver } & MAP30 & Hep G2 & Balb/C nude mice & Fang et al., 2012b \\
\hline & RNase MC2 & Hep G2 & Balb/C nude mice & Fang et al., 2012c \\
\hline & MC lectin & Hep G2, PLC/PRF/5 & Nude mice & Zhang et al., 2015 \\
\hline & Cucurbitane-type triterpene glycosides & Hep G2, Нер 3B & & Yue et al., 2019 \\
\hline \multirow[t]{4}{*}{ Prostate } & MC extract & PC3, LNCaP & TRAMP mice & Ru et al., 2011 \\
\hline & MC leaf extract, Kuguacin J & LNCaP, PNT1A & & Pitchakarn et al., 2011 \\
\hline & MC leaf extract & PLS10 & Nude mice & Pitchakarn et al., 2010 \\
\hline & MCP30 & LNCaP, PC-3, RWPE-1, PIN & Nude mice & Xiong et al., 2009 \\
\hline Bladder & 48-127/momordin IT & $\mathrm{T} 24$ & & Battelli et al., 1996 \\
\hline Glioma & Transferrin/momordin IT & HS683, U251 & & Gosselaar et al., 2002 \\
\hline \multirow[t]{2}{*}{ Lymphoma } & Ber-H2/momordin IT & $\mathrm{ALCL}$ & SCID mice & Terenzi et al., 1996 \\
\hline & OM124/momordin IT & Daudi, EHM, BJAB, Raji, BM21 & SCID mice & Bolognesi et al., 1998 \\
\hline \multirow[t]{3}{*}{ Leukemia } & Ethanol MC extracts & $\begin{array}{l}\text { ED, Su9T01, S1T, HUT-102, MT-2, } \\
\text { Jurkat, MOLT-4 }\end{array}$ & & Kai et al., 2011 \\
\hline & Ethanol MC extracts & HL60 & Balb/cAnNCrj-nu/nu mice & Kobori et al., 2008b \\
\hline & Anti-CD5/momordin IT & $\begin{array}{l}\text { Peripheral blood mononuclear cells, } \\
\text { Jurkat }\end{array}$ & nu/nu mice & Porro et al., 1993 \\
\hline
\end{tabular}

anticancer therapies, due to their ability to prevent cancer progression (Salehi et al., 2018). MC extracts have been investigated mainly for their potential use as chemo-preventive agents; many studies have evaluated the efficacy of MC extracts or purified components against different tumor derived cells, suggesting that dietary consumption of $\mathrm{MC}$ could help to lower risk of several cancers. Anti-proliferative and immunomodulatory effects were reported in the majority of studies (Nerurkar and Ray, 2010). It is thought that MC extracts' anti-cancer properties could rely on the ability to modulate several de-regulated signaling pathways in different type of cancer, like MAPK pathway, Akt/mTOR/p70S6K pathway through activation of AMPK, Wnt/ $\beta$-catenin signaling pathway and through the modulation of cell cycle proteins, thereby inducing cell cycle arrest or inducing apoptosis or other cell death pathways. Three recently identified MC cucurbitanetype triterpene glycosides showed significant anti-tumor activity in hepatic carcinoma derived cell lines (Yue et al., 2019). Given the influence of MC extracts on several inflammatoryrelated signaling pathways, it is possible that $\mathrm{MC}$ antiinflammatory properties may play a major role in its efficacy as tumor-preventive agent (Farooqi et al., 2018). To date, anti-cancer activity has been only observed in cancer cell lines and xenografted mice, and there is a need of further studies to elucidate the possible use of $\mathrm{MC}$ extracts as nutraceuticals in the treatment of cancer. A significant antitumor activity was reported for some MC proteins belonging to RIP family (Bolognesi et al., 2016). These proteins are potent inhibitors of cell translation and they have been extensively used for the production of anti-cancer drugs, particularly in the form of immunoconjugates or ITs, to obtain selective toxic protein delivery to target malignant cells (Polito et al., 2016b).

Although the lack of clinical data demonstrating the antitumor effect of MC components on humans, the whole results available in the literature make highly plausible a protective effect of MC both in the initiation of the tumor cell and during tumor progression. It is well known that the initial neoplastic transformation can be favored by oxidative stress that could be prevented by MC components. Tumor progression toward malignity is strongly related to chronic inflammation that is responsible for tumor invasion of surrounding normal tissues and angiogenesis. Again, the MC components could exert their anti-tumor effects by modulation of the inflammation status. 
The main mechanisms of MC anti-tumor action are summarized in Figure 1.

\section{SAFETY OF Momordica charantia}

Despite the wide MC usage in several traditional medicine, mainly for T2DM, there are quite scarce data from clinical trials and the few published studies enrolled a limited number of patients, for these reasons, safety data are more often derived from animal models. This lack of standardization in clinical studies still represents a limitation in the recognition of the therapeutic value of $\mathrm{MC}$ by a part of the scientific community. MC efficacy and safety have been comprehensively described by Basch et al. (2003). A recent meta-analysis highlighted the scarcity of data from clinical trials and the need for more structured and well-conducted studies (Peter et al., 2019).

Momordica charantia drugs should be always avoided by subjects that reported allergy to other plants from Cucurbitaceae. Individuals with glucose-6-phosphate dehydrogenase deficiency can develop favism after MC consumption (Raman and Lau, 1996). People wishing to procreate should consider with caution the daily use of MC, as it strongly reduced fertility in animal models (Stepka et al., 1974). As well as great caution should be used in the consumption of MC during pregnancy, since proteins contained in MC extracts showed abortive properties in animals (Basch et al., 2003). Caution is required also in patients with liver disease, because transaminase augment, although without histopathological alterations, was reported in animals. The most serious adverse effects in humans were reported in two small children that experienced a strong reduction of glycaemia after drinking MC based beverage on an empty stomach: between 1 and $2 \mathrm{~h}$ after ingestion, the children had convulsions followed by hypoglycemic coma (Raman and Lau, 1996). Other data on pediatric dosages are lacking.

A case of acute interstitial nephritis was reported in a 60years male with T2DM and hypertension that used hyponidd, an ayurvedic drug containing $M$. charantia. The patient took one hyponidd tablet daily for 1 week before the onset of his symptoms: edema and a decrease in urine, which progressed to complete anuria in 2-3 days (Beniwal et al., 2017). The toxicity for kidney was already reported in mice treated with MC $4 \mathrm{~g} / \mathrm{kg}$ for more than a week (Mardani et al., 2014).

\section{CONCLUSION}

About two third of world population continue to prefer local folk medicine to industrial drugs, mainly for economic reasons

\section{REFERENCES}

Alam, M. A., Uddin, R., Subhan, N., Rahman, M. M., Jain, P., and Reza, H. M. (2015). Beneficial role of bitter melon supplementation in obesity and related complications in metabolic syndrome. J. Lipids 2015:496169. doi: 10.1155/2015/49 6169 but in many cases also because of the fidelity to a traditional life style. The interest in plant derived medicinal products is increasing also in the occidental countries because these kinds of drugs are considered more "natural" and thus less toxic (often erroneously). Bitter melon is commonly used as a natural drug, mainly for the treatment of T2DM, but also as anti-inflammatory and anti-oxidant. It is well known the MC contribute in lowering glycaemia in T2DM patients. Moreover, the above reported researches attesting the MC anti-inflammatory effects seem to indicate the possible contribute of MC preparations also to reduce analgesic drug consumption in inflammatory related diseases.

However, it should be considered that the variability of preparation and the differences in cultivar and plant variety, the stage of harvest, the part of plant used and other factors can contribute to the discordant findings across the literature and often make difficult to fix the optimal dosage in terms of both efficacy and safety.

In addition, some considerations should be taken into account about MC side effects and interaction with conventional drugs: (i) for patients assuming $\mathrm{MC}$ at high doses and for prolonged periods clinical signs attributable to renal distress should not be underestimated; (ii) caution should be used when MC is taken together with other blood glucose-reducing agents because of the possible additive effects.

In conclusion, more trials are necessary to establish MC efficacy and safety with the aim to better utilize this precious natural resource.

\section{AUTHOR CONTRIBUTIONS}

All authors collected the literature, wrote, and revised the manuscript.

\section{FUNDING}

This study was supported by the University of Bologna with funds for selected research topics and by Pallotti's Legacy for Cancer Research.

\section{SUPPLEMENTARY MATERIAL}

The Supplementary Material for this article can be found online at: https://www.frontiersin.org/articles/10.3389/fphar. 2019.00486/full\#supplementary-material

FIGURE S1 | Chemical structures of the main bioactive Momordica charantia constituents.

Aljohi, A., Matou-Nasri, S., and Ahmed, N. (2016). Antiglycation and antioxidant properties of Momordica charantia. PLoS One 11:e0159985. doi: 10.1371/ journal.pone.0159985

Bai, J., Zhu, Y., and Dong, Y. (2016). Response of gut microbiota and inflammatory status to bitter melon (Momordica charantia L.) in high fat diet induced obese rats. J. Ethnopharmacol. 194, 717-726. doi: 10.1016/j.jep.2016.1 0.043 
Bai, J., Zhu, Y., and Dong, Y. (2018). Obese rats supplemented with bitter melon display marked shifts in the expression of genes controlling inflammatory response and lipid metabolism by RNA-Seq analysis of colonic mucosa. Genes Genomics 40, 561-567. doi: 10.1007/s13258-017-0642-4

Bao, B., Chen, Y. G., Zhang, L., Na, X. Y., Wang, X., Liu, J., et al. (2013). Momordica charantia, (bitter melon) reduces obesity-associated macrophage and mast cell infiltration as well as inflammatory cytokine expression in adipose tissues. PLoS One 8:e84075. doi: 10.1371/journal.pone.0084075

Basch, E., Gabardi, S., and Ulbricht, C. (2003). Bitter melon (Momordica charantia): a review of efficacy and safety. Am. J. Health Syst. Pharm. 60, 356-359. doi: 10.1093/ajhp/60.4.356

Battelli, M. G., Polito, L., Bolognesi, A., Lafleur, L., Fradet, Y., and Stirpe, F. (1996). Toxicity of ribosome-inactivating proteins-containing immunotoxins to a human bladder carcinoma cell line. Int. J. Cancer 65, 485-490. doi: 10.1002/ (sici)1097-0215(19960208)65:4<485::aid-ijc16>3.0.co;2-9

Battelli, M. G., Polito, L., Bortolotti, M., and Bolognesi, A. (2016). Xanthine oxidoreductase-derived reactive species: physiological and pathological effects. Oxid. Med. Cell Longev. 2016:3527579. doi: 10.1155/2016/3527579

Battelli, M. G., Polito, L., Bortolotti, M., and Bolognesi, A. (2018). Metabolic syndrome and cancer risk: the role of xanthine oxidoreductase. Redox Biol. 21:101070. doi: 10.1016/j.redox.2018.101070

Beniwal, P., Gaur, N., Singh, S. K., Raveendran, N., and Malhotra, V. (2017). How harmful can herbal remedies be? A case of severe acute tubulointerstitial nephritis. Indian J. Nephrol. 27, 459-461. doi: 10.4103/ijn.IJN_313_16

Biswas, S. K. (2016). Does the interdependence between oxidative stress and inflammation explain the antioxidant paradox? Oxid. Med. Cell Longev. 2016:5698931. doi: 10.1155/2016/5698931

Bolognesi, A., Bortolotti, M., Maiello, S., Battelli, M. G., and Polito, L. (2016). Ribosome-inactivating proteins from plants: a historical overview. Molecules 21:E1627. doi: 10.3390/molecules21121627

Bolognesi, A., Tazzari, P. L., Olivieri, F., Polito, L., Lemoli, R., Terenzi, A., et al. (1998). Evaluation of immunotoxins containing single-chain ribosomeinactivating proteins and an anti-CD22 monoclonal antibody (OM124): in vitro and in vivo studies. Br. J. Haematol. 101, 179-188. doi: 10.1046/j.1365-2141. 1998.00665.x

Cao, D., Sun, Y., Wang, L., He, Q., Zheng, J., Deng, F., et al. (2015). Alphamomorcharin $(\alpha-\mathrm{MMC})$ exerts effective anti-human breast tumor activities but has a narrow therapeutic window in vivo. Fitoterapia 100, 139-149. doi: 10.1016/j.fitote.2014.11.009

Chao, C. Y., Sung, P. J., Wang, W. H., and Kuo, Y. H. (2014). Anti-inflammatory effect of Momordica charantia in sepsis mice. Molecules 19, 12777-12788. doi: 10.3390/molecules 190812777

Cheng, H. L., Kuo, C. Y., Liao, Y. W., and Lin, C. C. (2012). EMCD, a hypoglycemic triterpene isolated from Momordica charantia wild variant, attenuates TNFalpha-induced inflammation in FL83B cells in an AMP-activated protein kinase-independent manner. Eur. J. Pharmacol. 689, 241-248. doi: 10.1016/j. ejphar.2012.05.033

Ciou, S. Y., Hsu, C. C., Kuo, Y. H., and Chao, C. Y. (2014). Effect of wild bitter gourd treatment on inflammatory responses in BALB/c mice with sepsis. Biomedicine (Taipei) 4:17. doi: 10.7603/s40681-014-0017-y

Dandawate, P. R., Subramaniam, D., Padhye, S. B., and Anant, S. (2016). Bitter melon: a panacea for inflammation and cancer. Chin. J. Nat. Med. 14, 81-100. doi: 10.1016/S1875-5364(16)60002-X

Deep, G., Dasgupta, T., Rao, A. R., and Kale, R. K. (2004). Cancer preventive potential of Momordica charantia L. against benzo(a)pyrene induced forestomach tumourigenesis in murine model system. Indian J. Exp. Biol. 42, 319-322.

Deng, Z., Yuan, C., Yang, J., Peng, Y., Wang, W., Wang, Y., et al. (2019). Behavioral defects induced by chronic social defeat stress are protected by Momordica charantia polysaccharides via attenuation of JNK3/PI3K/AKT neuroinflammatory pathway. Ann. Transl. Med. 7:6. doi: 10.21037/atm.2018. 12.08

Emre, B., Korkmaz, Ö, Temamoğullari, F., Zonturlu, A. K., Koyuncu, İ, Özkaraca, M., et al. (2017). Effect of intrauterine infusion of Momordica charantia L. on oxidative stress and pregnancy rate in infertile cows. J. Vet. Res. 61, 489-496. doi: 10.1515/jvetres-2017-0063

Fachinan, R., Fagninou, A., Nekoua, M. P., Amoussa, A. M., Adjagba, M., Lagnika, L., et al. (2017a). Evidence of immunosuppressive and th2 immune polarizing effects of antidiabetic Momordica charantia fruit juice. Biomed. Res. Int. 2017:9478048. doi: 10.1155/2017/9478048

Fachinan, R., Yessoufou, A., Nekoua, M. P., and Moutairou, K. (2017b). Effectiveness of antihyperglycemic effect of Momordica charantia: implication of t-cell cytokines. Evid. Based Complement. Alternat. Med. 2017:3707046. doi: $10.1155 / 2017 / 3707046$

Fan, J. M., Luo, J., Xu, J., Zhu, S., Zhang, Q., Gao, D. F., et al. (2008). Effects of recombinant MAP30 on cell proliferation and apoptosis of human colorectal carcinoma LoVo cells. Mol. Biotechnol. 39, 79-86. doi: 10.1007/s12033-0089034-y

Fang, E. F., Zhang, C. Z., Fong, W. P., and Ng, T. B. (2012a). RNase MC2: a new Momordica charantia ribonuclease that induces apoptosis in breast cancer cells associated with activation of MAPKs and induction of caspase pathways. Apoptosis 17, 377-387. doi: 10.1007/s10495-011-0684-z

Fang, E. F., Zhang, C. Z., Wong, J. H., Shen, J. Y., Li, C. H., and Ng, T. B. (2012b). The MAP30 protein from bitter gourd (Momordica charantia) seeds promotes apoptosis in liver cancer cells in vitro and in vivo. Cancer Lett. 324, 66-74. doi: 10.1016/j.canlet.2012.05.005

Fang, E. F., Zhang, C. Z., Zhang, L., Fong, W. P., and Ng, T. B. (2012c). In vitro and in vivo anticarcinogenic effects of RNase MC2, a ribonuclease isolated from dietary bitter gourd, toward human liver cancer cells. Int. J. Biochem. Cell Biol. 44, 1351-1360. doi: 10.1016/j.biocel.2012.04.013

Farooqi, A. A., Khalid, S., Tahir, F., Sabitaliyevich, U. Y., Yaylim, I., Attar, R., et al. (2018). Bitter gourd (Momordica charantia) as a rich source of bioactive components to combat cancer naturally: are we on the right track to fully unlock its potential as inhibitor of deregulated signaling pathways. Food Chem. Toxicol. 119, 98-105. doi: 10.1016/j.fct.2018.05.024

Ghous, T., Aziz, N., Mehmood, Z., and Andleeb, S. (2015). Comparative study of antioxidant, metal chelating and antiglycation activities of Momordica charantia flesh and pulp fractions. Pak. J. Pharm. Sci. 28, 1217-1223.

Gong, J., Sun, F., Li, Y., Zhou, X., Duan, Z., Duan, F., et al. (2015). Momordica charantia polysaccharides could protect against cerebral ischemia/reperfusion injury through inhibiting oxidative stress mediated c-Jun N-terminal kinase 3 signaling pathway. Neuropharmacology 91, 123-134. doi: 10.1016/j. neuropharm.2014.11.020

Gosselaar, P. H., van-Dijk, A. J., de-Gast, G. C., Polito, L., Bolognesi, A., Vooijs, W. C., et al. (2002). Transferrin toxin but not transferrin receptor immunotoxin is influenced by free transferrin and iron saturation. Eur. J. Clin. Invest. 32, 61-69. doi: 10.1046/j.1365-2362.2002.0320s1061.x

Grossmann, M. E., Mizuno, N. K., Dammen, M. L., Schuster, T., Ray, A., and Cleary, M. P. (2009). Eleostearic acid inhibits breast cancer proliferation by means of an oxidation-dependent mechanism. Cancer Prev. Res. 2, 879-886. doi: 10.1158/1940-6207.CAPR-09-0088

Grover, J. K., and Yadav, S. P. (2004). Pharmacological actions and potential uses of Momordica charantia: a review. J. Ethnopharmacol. 93, 123-132. doi: 10.1016/j. jep.2004.03.035

Güdr, A. (2016). Influence of total anthocyanins from bitter melon (Momordica charantia Linn.) as antidiabetic and radical scavenging agents. Iran J. Pharm. Res. 15, 301-309.

Gupta, M., Sharma, S., Gautam, A. K., and Bhadauria, R. (2011). Momordica charantia Linn, (karela): nature's silent healer. Int. J. Pharm. Sci. Rev. Res. 11, $32-37$.

Gürdal, B., and Kültür, S. (2013). An ethnobotanical study of medicinal plants in Marmaris (Muğla, Turkey). J. Ethnopharmacol. 146, 113-126. doi: 10.1016/j.jep. 2012.12.012

He, Q., Li, Y., Li, H., Zhang, P., Zhang, A., You, L., et al. (2018). Hypolipidemic and antioxidant potential of bitter gourd (Momordica charantia L.) leaf in mice fed on a high-fat diet. Pak. J. Pharm. Sci. 31, 1837-1843.

Hsu, C., Fang, S., Lju, C., and Chen, Y. (2013). Inhibitory effects of new varieties of bitter melon on lipopolysaccharide-stimulated inflammatory response in RAW 264.7 cells. J. Funct. Foods 5, 1829-1837. doi: 10.1016/j.jff.2013. 09.002

Huang, W. C., Tsai, T. H., Huang, C. J., Li, Y. Y., Chyuan, J. H., Chuang, L. T., et al. (2015). Inhibitory effects of wild bitter melon leaf extract on Propionibacterium acnes-induced skin inflammation in mice and cytokine production in vitro. Food Funct. 8, 2550-2560. doi: 10.1039/c5fo0 $0550 \mathrm{~g}$ 
Jones, L. D., Pangloli, P., Krishnan, H. B., and Dia, V. P. (2018). BG-4, a novel bioactive peptide from Momordica charantia, inhibits lipopolysaccharideinduced inflammation in THP-1 human macrophages. Phytomedicine 42, 226232. doi: 10.1016/j.phymed.2018.03.047

Kai, H., Akamatsu, E., Torii, E., Kodama, H., Yukizaki, C., Sakakibara, Y., et al. (2011). Inhibition of proliferation by agricultural plant extracts in seven human adult T-cell leukaemia (ATL)-related cell lines. J. Nat. Med. 65, 651-655. doi: 10.1007/s11418-011-0510-5

Kim, H. Y., Sin, S. M., Lee, S., Cho, K. M., and Cho, E. J. (2013). The butanol fraction of bitter melon (Momordica charantia) scavenges free radicals and attenuates oxidative stress. Prev. Nutr. Food Sci. 18, 18-22. doi: 10.3746/pnf. 2013.18.1.018

Kim, K. B., Lee, S., Kang, I., and Kim, J. H. (2018). Momordica charantia ethanol extract attenuates $\mathrm{H} 2 \mathrm{O} 2$-induced cell death by its antioxidant and anti-apoptotic properties in human neuroblastoma SK-N-MC cells. Nutrients 10:E1368. doi: 10.3390/nu10101368

Kobori, M., Nakayama, H., Fukushima, K., Ohnishi-Kameyama, M., Ono, H., Fukushima, T., et al. (2008a). Bitter gourd suppresses lipopolysaccharideinduced inflammatory responses. J. Agric. Food Chem. 56, 4004-4011. doi: $10.1021 /$ jf800052y

Kobori, M., Ohnishi-Kameyama, M., Akimoto, Y., Yukizaki, C., and Yoshida, M. (2008b). Alpha-eleostearic acid and its dihydroxy derivative are major apoptosis-inducing components of bitter gourd. J. Agric. Food Chem. 56, 10515-10520. doi: 10.1021/jf8020877

Kohno, H., Yasui, Y., Suzuki, R., Hosokawa, M., Miyashita, K., and Tanaka, T. (2004). Dietary seed oil rich in conjugated linolenic acid from bitter melon inhibits azoxymethane-induced rat colon carcinogenesis through elevation of colonic PPARgamma expression and alteration of lipid composition. Int. J. Cancer 110, 896-901. doi: 10.1002/ijc.20179

Kwatra, D., Subramaniam, D., Ramamoorthy, P., Standing, D., Moran, E., Velayutham, R., et al. (2013). Methanolic extracts of bitter melon inhibit colon cancer stem cells by affecting energy homeostasis and autophagy. Evid. Based Complement. Alternat. Med. 2013:702869. doi: 10.1155/2013/702869

Lee-Huang, S., Huang, P. L., Sun, Y., Chen, H. C., Kung, H. F., Huang, P. L., et al. (2000). Inhibition of MDA-MB-231 human breast tumor xenografts and HER2 expression by anti-tumor agents GAP31 and MAP30. Anticancer Res. 20, 653-659.

Li, C. J., Tsang, S. F., Tsai, C. H., Tsai, H. Y., Chyuan, J. H., and Hsu, H. Y. (2012a). Momordica charantia extract induces apoptosis in human cancer cells through caspase- and mitochondria-dependent pathways. Evid. Based Complement. Alternat. Med. 2012:261971. doi: 10.1155/2012/261971

Li, Y., Yin, L., Zheng, L., Xu, L., Xu, Y., Zhao, Y., et al. (2012b). Application of highspeed counter-current chromatography coupled with a reverse micelle solvent system to separate three proteins from Momordica charantia. J. Chromatogr. $B$ Analyt. Technol. Biomed. Life Sci. 89, 77-82. doi: 10.1016/j.jchromb.2012.03.017

Liaw, C. C., Huang, H. C., Hsiao, P. C., Zhang, L. J., Lin, Z. H., Hwang, S. Y.,

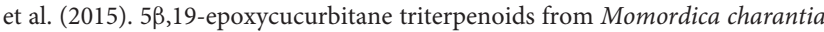
and their anti-inflammatory and cytotoxic activity. Planta Med. 81, 62-70. doi: 10.1055/s-0034-1383307

Lii, C. K., Chen, H. W., Yun, W. T., and Liu, K. L. (2009). Suppressive effects of wild bitter gourd (Momordica charantia Linn. var. abbreviata ser.) fruit extracts on inflammatory responses in RAW264.7 macrophages. J. Ethnopharmacol. 122, 227-233. doi: 10.1016/j.jep.2009.01.028

Lin, Z. Y., Liu, X., Yang, F., and Yu, Y. Q. (2012). Structural characterization and identification of five triterpenoid saponins isolated from Momordica cochinchinensis extracts by liquid chromatography/tandem mass spectrometry. Int. J. Mass Spectrom. 32, 43-66. doi: 10.1016/j.ijms.2012.07.022

Liu, C. H., Yen, M. H., Tsang, S. F., Gan, K. H., Hsu, H. Y., and Lin, C. N. (2010). Antioxidant triterpenoids from the stems of Momordica charantia. Food Chem. 118, 751-756. doi: 10.1016/j.foodchem.2009.05.058

Mardani, S., Nasri, H., Hajian, S., Ahmadi, A., Kazemi, R., and Rafieian-Kopaei, M. (2014). Impact of Momordica charantia extract on kidney function and structure in mice. J. Nephropathol. 3, 35-40. doi: 10.12860/jnp.2014.08

Marelli, G., Sica, A., Vannucci, L., and Allavena, P. (2017). Inflammation as target in cancer therapy. Curr. Opin. Pharmacol. 35, 57-65. doi: 10.1016/j.coph.2017. 05.007

Minihane, A. M., Vinoy, S., Russell, W. R., Baka, A., Roche, H. M., Tuohy, K. M., et al. (2015). Low-grade inflammation, diet composition and health: current research evidence and its translation. Br. J. Nutr. 114, 999-1012. doi: 10.1017/ S0007114515002093

Myojin, C., Enami, N., Nagata, A., Yamaguchi, T., Takamura, H., and Matoba, T. (2008). Changes in the radical-scavenging activity of bitter gourd (Momordica charantia L.) during freezing and frozen storage with or without blanching. J. Food Sci. 73, C546-C550. doi: 10.1111/j.1750-3841.2008.00886.x

Nagasawa, H., Watanabe, K., and Inatomi, H. (2002). Effects of bitter melon (Momordica charantia L.) or ginger rhizome (Zingiber officinale Rosc) on spontaneous mammary tumorigenesis in SHN mice. Am. J. Chin. Med. 30, 195-205. doi: 10.1142/S0192415X02000302

Nerurkar, P., and Ray, R. B. (2010). Bitter melon: antagonist to cancer. Pharm. Res. 27, 1049-1053. doi: 10.1007/s11095-010-0057-2

Nerurkar, P. V., Johns, L. M., Buesa, L. M., Kipyakwai, G., Volper, E., Sato, R., et al. (2011). Momordica charantia (bitter melon) attenuates high-fat dietassociated oxidative stress and neuroinflammation. J. Neuroinflamm. 8, 1-19. doi: 10.1186/1742-2094-8-64

Nyam, K. L., Tan, C. P., Lai, O. M., Long, K., and Che Man, Y. B. (2013). Physicochemical properties and bioactive compounds of selected seed oils. LWT-Food Sci. Technol. 42, 1396-1403. doi: 10.1016/j.lwt.2009.03.006

Padmashree, A., Sharma, G. K., Semwal, A. D., and Bawa, A. S. (2010). Studies on antioxygenic activity of bitter gourd (Momordica charantia) and its fractions using various in vitro models. J. Sci. Food Agric. 91, 776-782. doi: 10.1002/jsfa. 4251

Peter, E. L., Kasali, F. M., Deyno, S., Mtewa, A., Nagendrappa, P. B., Tolo, C. U., et al. (2019). Momordica charantia L. lowers elevated glycaemia in type 2 diabetes mellitus patients: aystematic review and meta-analysis. J. Ethnopharmacol. 231, 311-324. doi: 10.1016/j.jep.2018.10.033

Pitchakarn, P., Ogawa, K., Suzuki, S., Takahashi, S., Asamoto, M., Chewonarin, T., et al. (2010). Momordica charantia leaf extract suppresses rat prostate cancer progression in vitro and in vivo. Cancer Sci. 101, 2234-2240. doi: 10.1111/j. 1349-7006.2010.01669.x

Pitchakarn, P., Suzuki, S., Ogawa, K., Pompimon, W., Takahashi, S., Asamoto, M., et al. (2011). Induction of G1 arrest and apoptosis in androgendependent human prostate cancer by Kuguacin J, a triterpenoid from Momordica charantia leaf. Cancer Lett. 306, 142-150. doi: 10.1016/j.canlet.2011. 02.041

Polito, L., Bortolotti, M., Maiello, S., Battelli, M. G., and Bolognesi, A. (2016a). Plants producing ribosome-inactivating proteins in traditional medicine. Molecules 21:E1560. doi: 10.3390/molecules21111560

Polito, L., Djemil, A., and Bortolotti, M. (2016b). Plant toxin-based immunotoxins for cancer therapy: a short overview. Biomedicines 4:E12. doi: 10.3390/ biomedicines4020012

Porro, G., Bolognesi, A., Caretto, P., Gromo, G., Lento, P., Mistza, G., et al. (1993). In vitro and in vivo properties of an anti-CD5-momordin immunotoxin on normal and neoplastic T lymphocytes. Cancer Immunol. Immunother. 36, 346-350. doi: 10.1007/bf01741174

Raish, M. (2017). Momordica charantia polysaccharides ameliorate oxidative stress, hyperlipidemia, inflammation, and apoptosis during myocardial infarction by inhibiting the NF-кB signaling pathway. Int. J. Biol. Macromol. 97, 544-551. doi: 10.1016/j.ijbiomac.2017.01.074

Raish, M., Ahmad, A., Ansari, M. A., Alkharfy, K. M., Aljenoobi, F. I., Jan, B. L., et al. (2018). Momordica charantia polysaccharides ameliorate oxidative stress, inflammation, and apoptosis in ethanol-induced gastritis in mucosa through NF-kB signaling pathway inhibition. Int. J. Biol. Macromol. 111, 193-199. doi: 10.1016/j.ijbiomac.2018.01.008

Raman, A., and Lau, C. (1996). Anti-diabetic properties and phytochemistry of Momordica charantia L. (Cucurbitaceae). Phytomedicine 2, 349-362. doi: 10.1016/S0944-7113(96)80080-8

Ray, R. B., Raychoudhuri, A., Steele, R., and Nerurkar, P. (2010). Bitter melon (Momordica charantia) extract inhibits breast cancer cell proliferation by modulating cell cycle regulatory genes and promotes apoptosis. Cancer Res. 70, 1925-1931. doi: 10.1158/0008-5472.CAN-09-3438

Rios, J. L., Escandell, J. M., and Recio, M. C. (2005). Studies in Natural Products Chemistry, ed. Atta-ur-Rahman, Vol. 32. Amsterdam: Elsevier, 429.

Ru, P., Steele, R., Nerurkar, P. V., Phillips, N., and Ray, R. B. (2011). Bitter melon extract impairs prostate cancer cell-cycle progression and delays prostatic intraepithelial neoplasia in TRAMP model. Cancer Prev. Res. 4, 2122-2130. doi: 10.1158/1940-6207.CAPR-11-0376 
Saad, D. Y., Soliman, M. M., Baiomy, A. A., Yassin, M. H., and El-Sawy, H. B. (2017). Effects of Karela (Bitter Melon; Momordica charantia) on genes of lipids and carbohydrates metabolism in experimental hypercholesterolemia: biochemical, molecular and histopathological study. BMC Complement. Altern. Med. 17:319. doi: 10.1186/s12906-017-1833-x

Salehi, B., Zucca, P., Sharifi-Rad, M., Pezzani, R., Rajabi, S., Setzer, W. N., et al. (2018). Phytotherapeutics in cancer invasion and metastasis. Phytother. Res. 32, 1425-1449. doi: 10.1002/ptr.6087

Scartezzini, P., and Speroni, E. (2000). Review on some plants of Indian traditional medicine with antioxidant activity. J. Ethnopharmacol. 71, 23-43. doi: 10.1016/ S0378-8741(00)00213-0

Schrot, J., Weng, A., and Melzig, M. F. (2015). Ribosome-inactivating and related proteins. Toxins 7, 1556-1615. doi: 10.3390/toxins7051556

Soo May, L., Sanip, Z., Ahmed Shokri, A., Abdul Kadir, A., and Md Lazin, M. R. (2018). The effects of Momordica charantia (bitter melon) supplementation in patients with primary knee osteoarthritis: a single-blinded, randomized controlled trial. Complement. Ther. Clin. Pract. 32, 181-186. doi: 10.1016/j.ctcp. 2018.06.012

Stepka, W., Wilson, K. E., and Madge, G. E. (1974). Antifertility investigation on Momordica. Lloydia 37, 645.

Sung, H. C., Liu, C. W., Hsiao, C. Y., Lin, S. R., Yu, I. S., Lin, S. W., et al. (2018). The effects of wild bitter gourd fruit extracts on ICAM-1 expression in pulmonary epithelial cells of C57BL/6J mice and microRNA-221/222 knockout mice: involvement of the miR-221/-222/PI3K/AKT/NF- $\mathrm{B}$ pathway. Phytomedicine 42, 90-99. doi: 10.1016/j.phymed.2018.03.023

Svobodova, B., Barros, L., Calhelha, R. C., Heleno, S., Alves, M. J., Walcott, S., et al. (2017). Bioactive properties and phenolic profile of Momordica charantia L. medicinal plant growing wild in Trinidad and Tobago. Ind. Crops Prod. 98, 365-373. doi: 10.1016/j.indcrop.2016.10.046

Tan, H. F., and Gan, C. Y. (2016). Polysaccharide with antioxidant, $\alpha$-amylase inhibitory and ACE inhibitory activities from Momordica charantia. Int. J. Biol. Macromol. 85, 487-496. doi: 10.1016/j.ijbiomac.2016.01.023

Terenzi, A., Bolognesi, A., Pasqualucci, L., Flenghi, L., Pileri, S., Stein, H., et al. (1996). Anti-CD30 (BER = H2) immunotoxins containing the type-1 ribosomeinactivating proteins momordin and PAP-S (pokeweed antiviral protein from seeds) display powerful antitumour activity against CD30+ tumour cells in vitro and in SCID mice. Br. J. Haematol. 92, 872-879. doi: 10.1046/j.13652141.1995.404942.x

Tripathi, U. N., and Chandra, D. (2010). Anti-hyperglycemic and anti-oxidative effect of aqueous extract of Momordica charantia pulp and Trigonella foenum graecum seed in alloxan-induced diabetic rats. Indian J. Biochem. Biophys. 47, 227-233.

Tsai, T. H., Huang, W. C., Ying, H. T., Kuo, Y. H., Shen, C. C., Lin, Y. K., et al. (2016). Wild bitter melon leaf extract inhibits Porphyromonas gingivalis-induced inflammation: identification of active compounds through bioassay-guided isolation. Molecules 21:454. doi: 10.3390/molecules210 40454

Weng, J. R., Bai, L. Y., Chiu, C. F., Hu, J. L., Chiu, S. J., and Wu, C. Y. (2013). Cucurbitane triterpenoid from Momordica charantia induces apoptosis and autophagy in breast cancer cells, in part, through peroxisome proliferatoractivated receptor $\gamma$ activation. Evid. Based Complement. Alternat. Med. 2013:935675. doi: 10.1155/2013/935675

Xiong, S. D., Yu, K., Liu, X. H., Yin, L. H., Kirschenbaum, A., Yao, S., et al. (2009). Ribosome-inactivating proteins isolated from dietary bitter melon induce apoptosis and inhibit histone deacetylase-1 selectively in premalignant and malignant prostate cancer cells. Int. J. Cancer 125, 774-782. doi: 10.1002/ ijc. 24325

Xu, J., Cao, K., Li, Y., Zou, X., Chen, C., Szeto, I. M., et al. (2014). Bitter gourd inhibits the development of obesity-associated fatty liver in C57BL/6 mice fed a high-fat diet. J. Nutr. 144, 475-483. doi: 10.3945/jn.113.187450

Yadav, B. S., Yadav, R., Yadav, R. B., and Garg, M. (2016). Antioxidant activity of various extracts of selected gourd vegetables. J. Food Sci. Technol. 53, 1823-1833. doi: 10.1007/s13197-015-1886-0

Yang, W. S., Yang, E., Kim, M. J., Jeong, D., Yoon, D. H., Sung, G. H., et al. (2018). Momordica charantia inhibits inflammatory responses in murine macrophages via suppression of TAK1. Am. J. Chin. Med. 46, 435-452. doi: 10.1142/ S0192415X18500222

Yasui, Y., Hosokawa, M., Sahara, T., Suzuki, R., Ohgiya, S., Kohno, H., et al. (2005). Bitter gourd seed fatty acid rich in $9 \mathrm{c}, 11 \mathrm{t}, 13 \mathrm{t}$-conjugated linolenic acid induces apoptosis and up-regulates the GADD45, p53 and PPARgamma in human colon cancer Caco-2 cells. Prostaglandins Leukot Essent Fatty Acids 73, 113-119. doi: 10.1016/j.plefa.2005.04.013

Yoshime, L. T., de Melo, I. L. P., Sattler, J. A. G., de Carvalho, E. B. T., and ManciniFilho, J. (2016). Bitter gourd (Momordica charantia L.) seed oil as a naturally rich source of bioactive compounds for nutraceutical purposes. Nutrire 41:12. doi: 10.1186/s41110-016-0013-y

Yue, J., Sun, Y., Xu, J., Cao, J., Chen, G., Zhang, H., et al. (2019). Cucurbitane triterpenoids from the fruit of Momordica charantia L. and their anti-hepatic fibrosis and anti-hepatoma activities. Phytochemistry 157, 21-27. doi: 10.1016/ j.phytochem.2018.10.009

Zeng, Y., Guan, M., Li, C., Xu, L., Zheng, Z., Li, J., et al. (2018). Bitter melon (Momordica charantia) attenuates atherosclerosis in apo-E knock-out mice possibly through reducing triglyceride and anti-inflammation. Lipids Health Dis. 17:251. doi: 10.1186/s12944-018-0896-0

Zhang, C. Z., Fang, E. F., Zhang, H. T., Liu, L. L., and Yun, J. P. (2015). Momordica charantia lectin exhibits antitumor activity towards hepatocellular carcinoma. Invest. New Drugs 33, 1-11. doi: 10.1007/s10637-014-0156-8

Conflict of Interest Statement: The authors declare that the research was conducted in the absence of any commercial or financial relationships that could be construed as a potential conflict of interest.

Copyright (c) 2019 Bortolotti, Mercatelli and Polito. This is an open-access article distributed under the terms of the Creative Commons Attribution License (CC BY). The use, distribution or reproduction in other forums is permitted, provided the original author(s) and the copyright owner(s) are credited and that the original publication in this journal is cited, in accordance with accepted academic practice. No use, distribution or reproduction is permitted which does not comply with these terms. 